\title{
INFORMÁTICA NA SALA DE AULA: REALIDADE OU UTOPIA?
}

\author{
BORBA, Valdinéa Rodrigues de Souza ${ }^{1}$ \\ LIMA, Susana Marcele de ${ }^{2}$ \\ REIS, Sueli Antônia ${ }^{3}$
}

\begin{abstract}
RESUMO: O presente estudo tem como objetivo investigar e analisar como está se efetivando a inserção dos computadores nas escolas e como os docentes concebem o uso desta tecnologia. Como referenciais teóricos, esta pesquisa busca fundamentos nos estudos de Pierre Lévy e Serge Moscovici. A pesquisa qualitativa norteia esta investigação realizada em três escolas do interior do estado de São Paulo. Como procedimentos de coleta de dados, foram utilizados questionários semi-estruturados e observações de aulas, visando a identificar os possíveis fatores que podem interferir na utilização da informática em sala de aula, bem como as concepções das próprias docentes sobre o tema. Relacionando as concepções, reflexões e práticas pedagógicas observadas, foi possível estabelecer as seguintes categorias: 1) Uso do computador como instrumento de apoio à prática pedagógica; 2) Uso do computador como minimizador da exclusão digital dos discentes; 3) Docentes versus competência tecnológica e 4) Computadores como elementos de decoração nas escolas. Estas diferentes concepções contribuem para a discussão sobre os fatores determinantes nos processos de ensino e aprendizagem e na inclusão digital: a intervenção pedagógica eficaz, o papel da própria escola como instituição de ensino, a participação efetiva da comunidade escolar e dos próprios discentes. Esta investigação pretende contribuir, trazendo informações e questionamentos que levem o professor a refletir sobre sua práxis e sobre sua importância como responsável pelo uso do computador como aliado em seu fazer pedagógico.
\end{abstract}

Palavras-chave: Informática. Tecnologia Educacional. Sala de aula. Representações Sociais.

\begin{abstract}
The present study aims to investigate and to analyze how the insertion of computers in school is done, and how teachers conceive the use of this technology. As theoretical references, this work searches as theoretical basis Pierre Lévy and Serge Moscovici's studies. Qualitative research guides this inquiry realized in three schools of the interior of the state of São Paulo. As procedures of data collection, half-structuralized questionnaires and class comments were used, typing to identify possible factors that may interfere in the use of computer science in classroom, as well as the conceptions of the own teachers about this subject. Relating observed conceptions, reflections and pedagogical practices, it was possible to establish the follow categories: 1) Use of computer as instrument of practical support to pedagogical one; 2) Use of computer as minimizer of students' digital exclusion; 3) Teachers versus technological ability and, 4) Computers as pertaining to school adornments. These different conceptions contribute to the discussion about the determinant factors in the processes of teaching and learning and in the digital inclusion: effective pedagogical intervention, the role of school as a teaching institution and the effective participation of school community and of the own teachers. This investigation intends to contribute, bringing information and questionings that take the teacher to reflect on its praxis and on its importance as responsible for the use of computer as a partner in its pedagogical work.
\end{abstract}

Keywords: Computer science. Educational technology. Classroom. Social Representations.

1 Mestre em Educação. Prof. a Pedagogia FE/FFCL. E-mail: valdinea@feituverava.com.br

2 Graduanda em Pedagogia FE/FFCL.

3 Graduanda em Pedagogia.FE/FFCL 


\section{INTRODUÇÃO}

Este artigo é um produto parcial da pesquisa realizada para elaboração de Trabalho de Conclusão de Curso que traz, provisoriamente, o mesmo título. Objetiva investigar e analisar as concepções dos professores a respeito do uso da informática na sala de aula, como aliada em suas práticas pedagógicas.

Fundamentam esta pesquisa as concepções teóricas de Pierre Lévy e Serge Moscovici. Lévy advoga que a tecnologia da informática pode e deve ser amplamente utilizada nas escolas e que a não aceitação desta realidade e da inserção de seus alunos no universo das telecomunicações e da informática é ultrapassada e nociva. Moscovici, por sua vez, aponta que as representações sociais que as pessoas têm sobre algo, neste caso, os docentes sobre os computadores e seu uso, são fatores determinantes para suas ações.

\section{A EVOLUÇÃO DA TECNOLOGIA}

Desde o princípio de sua existência, o homem é levado a buscar meios de desenvolver técnicas para sua própria sobrevivência. A necessidade o leva à evolução e, aliada à sua inteligência, o ser humano é capaz de criar formas para resistir a toda e qualquer força da natureza. Descobriu-se que os elementos naturais poderiam ser usados a seu bel-prazer e, também, para solucionar seus problemas corriqueiros.

Mas, afinal, o que é tecnologia e que relação ela tem com tudo isso?

Tecnologia é uma palavra de origem grega: "tecnhe", que significa "ofício", "arte", "habilidade" e "logia", que significa "discurso", "conhecimento", "estudo" e "pensamento".

Lévy (1993/1998) declara que, na sociedade contemporânea, o termo tecnologia é usado para se referir a máquinas e, em especial, ao computador. Segundo ele, a tecnologia está vinculada ao desenvolvimento. Pode-se, então, afirmar que os diversos recursos tecnológicos foram criados pelo homem para seu progresso e conforto, e a Educação não poderia ficar à margem de tamanha evolução. Também, nessa área, foram criados vários instrumentos e técnicas específicas, bem como foram tomados emprestados recursos e instrumentos tecnológicos de outras áreas em prol do sucesso dos processos ensino e aprendizagem. A esse conjunto de instrumentos foi dado o nome de Tecnologia Educacional.

Segundo Leite (2003), a tecnologia educacional pode ser dividida em independente e dependente. De acordo com ela, as tecnologias independentes seriam aquelas que não dependem de recursos eletrônicos e elétricos para serem produzidos e/ou utilizados, enquanto que as dependentes, como a própria classificação aponta, não existiriam sem o uso de recursos elétricos e/ou eletrônicos. 


\section{A INFORMÁticA COMO ALIAdA DOS PROCESSOS DE ENSINO E APRENDIZAGEM}

O avanço tecnológico trouxe, consigo, inúmeras mudanças no contexto social em que estamos inseridos e se tornou, praticamente, impossível fugir dessa revolução, e de uma maneira mais intensa, da informática. As pessoas estão inseridas em uma realidade altamente informatizada, onde o uso de computadores passou a ser estritamente necessário, obrigando-as a uma adaptação imediata. Porém, embora essa mudança tenha um caráter de urgência, ainda há muitas questões que envolvem a inserção da informática nas salas de aula, e algumas delas serão tratadas a seguir.

\section{DIMENSÕES DA INFORMÁTICA NA EDUCAÇÃO}

\section{- Política}

O Brasil, como país emergente que é na tarefa de se aventurar no mercado da informática, coloca, em risco, suas relações com a hegemonia mundial. Mas o interesse do nosso país, de acordo com Almeida (2005), não é beneficiar somente a educação; seu grande foco é a indústria bélica, que depende muito dos recursos informatizados para existir. E a educação só entrou nessa disputa porque apenas as compras para a indústria da guerra não seriam suficientes para sustentar toda a estrutura do mercado do país.

Oliveira (1997) afirma que a inclusão do Brasil, neste plano, encontra ainda muitos obstáculos: falta de mão-de-obra especializada em escala suficiente para desenvolvimento de pesquisas nessa área; pressões políticas e econômicas dos países desenvolvidos, entre outros.

\section{- Sócio-Cultural}

Para Lévy:

Novas maneiras de pensar em conviver estão sendo cada vez mais no mundo das telecomunicações e da informática. As relações entre os homens, o trabalho, a própria inteligência dependem, na verdade da metamorfose incessante de dispositivos informacionais de todos os tipos. Escrita, leitura, visão, audição, criação, aprendizagem são capturados por uma informática cada vez mais avançada. Não se pode mais conceber a pesquisa cientifica sem uma aparelhagem complexa que redistribui as antigas divisões entre experiência e teoria. (1993, p. 7)

A proliferação da informática tem uma influência gigantesca na nossa vida e surte efeito em nossos hábitos, costumes, dogmas e em nossa cultura.

De acordo com Chaves; Setzer (1998), mesmo numa sociedade emergente, a tecnologia chegou com facilidade e podemos encontrá-la em qualquer segmento social, por exemplo, a produção industrial é mediada pela tecnologia, bem como o comércio, a medicina, a engenharia, a comunicação e etc. Afirmam, ainda, que o computador está ultrapassando as fronteiras do espaço e, como conseqüência, provocando uma maior interação entre as pessoas, eliminando 
distâncias geográficas.

\section{- Pedagógica}

Haetinger (2003) considera a informática a mais promissora ferramenta pedagógica dos últimos tempos. Quando se fala em informática educacional, logo se pensa em transmissão de conhecimentos "de" informática, que é a abordagem que se pretende com essa pesquisa; o que se busca é a informática utilizada como ferramenta aliada ao processo ensino - aprendizagem.

Para Valente, (1996) o que a escola tem feito pode ser chamado de "abordagem instrucionista", já que o "ensinar informática" é bem mais simples e cômodo do que a "abordagem didática" em que o professor utiliza o computador, fazendo dele um recurso pedagógico.

\section{AS REPRESENTAÇÕES SOCIAIS DA INFORMÁTICA NO ÂMBITO EDUCACIONAL}

Para Moscovici (1978; 1985), representações sociais são reveladoras de todas as formas de expressões e relações socias, de produção e consumo de objetos; expressam a maneira como uma pessoa enxerga os objetos sociais, que significado eles trazem para sua vida, e, dessa forma, determina suas atitudes perante os mesmos e a sociedade. Para ele, o estudo das representações

$[\ldots]$ se focaliza na maneira pela qual os seres humanos tentam captar e compreender as coisas que os circundam e resolver os 'lugares comuns' e quebra-cabeças que envolvem seu nascimento, seus corpos suas humilhações, o céu que vêem, os humores de seu vizinho e o poder a que se submetem.(1985, p.02)

Moscovici (1986) explica que as representações sociais são decisivas no julgamento das atitudes onde o conhecimento tem sua origem na observação, sendo assim, as representações sociais que as pessoas têm da realidade estão interligadas com suas experiências. "[...] o individuo sofre a pressão das representações dominantes da sociedade e é, nesse meio, que pensa ou exprime seus sentimentos" (2001, p. 22)

Com efeito, é importante compreender as representações sociais da informática e do computador no contexto escolar, pois é de extrema relevância seu significado na consciência individual e coletiva dos professores.

Advogando este mesmo pensamento, Belloni (2001) declara que as imposições feitas pela sociedade contemporânea demandam um novo tipo de profissional, o individuo dinâmico, flexível, critico, autônomo e capaz de tomar decisões imediatas.

Para Chaib (2002), o despreparo dos educadores na adaptação à sociedade informatizada mostra essa representação. $\mathrm{O}$ autor se preocupa com a rejeição que muitos professores manifestam frente às maquinas e argumenta que eles estão fortemente arraigados ao ensino tradicional, o que os impede de se adequar aos novos paradigmas, tornando, assim, as suas representações a maior barreira para a inserção da informática na sala de aula. 


\subsection{PERCURSO DE PESQUISA}

Os pressupostos da pesquisa qualitativa, discutidos por Mynaio (2001), foram referenciais na busca não apenas de números e estatísticas, mas sim, no engendramento dos dados coletados, relacionando-os aos fenômenos apontados.

Como procedimentos de coleta de dados foram utilizados questionários semi-estruturados e observações de aulas, visando a identificar os possíveis fatores que podem interferir na utilização da informática em sala de aula, bem como as concepções das próprias docentes sobre o tema.

Os sujeitos desta pesquisa foram 9 professoras de $1^{\mathrm{a}}$ a $4^{\mathrm{a}}$ série (Ciclo I do Ensino Fundamental) da rede pública e 4 professoras do mesmo ciclo de uma escola particular. A pesquisa foi desenvolvida em um município do interior do Estado de São Paulo, durante os meses de abril, maio, junho e julho de 2007. Atualmente, todas as escolas públicas estaduais deste município, bem como as particulares, possuem salas de informática, o que facilitou o desenvolvimento da pesquisa.

A busca incessante por escolas onde os computadores fossem efetivamente utilizados por seus professores e alunos encontrou, como resultados, o quadro que, a seguir, se configura.

\subsection{CATEGORIZANDO OS DADOS}

A partir da análise dos dados coletados, foi possível estabelecer grandes 4 categorias:

1) Uso do computador como instrumento de apoio à prática pedagógica

Fazem parte desta categoria os professores cujas respostas ao questionário e práticas pedagógicas contemplam de forma clara e objetiva o fundamento da implantação de salas equipadas com computadores, ou seja, que estes sirvam ao propósito educativo.

Verificou-se que 75\% (três professoras de escola particular) acreditam na informática como aliada aos processos de ensino-aprendizagem, contudo apenas uma destas professoras faz uso da tecnologia como instrumento em seu fazer pedagógico. Uma outra utiliza os computadores apenas para aulas de informática. Constatou-se, também, que 50\% das professoras de escola particular (ou seja, duas) têm domínio e afirmam saber utilizar o computador como recurso didático. Apenas uma professora de escola pública (11,11\% do total) utiliza a sala de informática em suas atividades com os alunos. Outra alegou utilizar, às vezes, a sala de informática. As observações de aulas práticas destas professoras confirmam as informações obtidas através do questionário.

Os dados levantados parecem indicar que as representações sociais das professoras com relação ao uso da informática na sala de aula, como mediadora e facilitadora de novas aprendizagens são positivas e confirmam a teoria.

\section{2) Uso do computador como minimizador da exclusão digital dos discentes.}

Aqui se encontram três professoras de escolas particulares (75\% do total geral) que 
afirmam não utilizar os computadores em suas aulas e com pretexto citam a existência de um professor especialista na área de informática.

Suas argumentações e práticas pedagógicas indicam que as salas de informática devem ser utilizadas apenas para inserir o aluno no mundo digital, sem nenhum cunho pedagógico, além de garantir a aprendizagem do uso desta ferramenta tecnológica.

\section{3) Docentes versus competência tecnológica.}

Verificou-se também que prática pedagógica esbarra em dificuldades e/ou limitações das professoras quanto ao uso do computador. Assim, cinco professoras de escolas públicas (55,55\% do total) alegam a inexistência, em suas casas, de computadores, o que dificultaria, segundo elas, o manuseio desta ferramenta tecnológica na escola. Outra professora foi mais direta e afirmou não dominar a tecnologia. Duas professoras de escola pública (22,22\% do total) confessam não saber como utilizar o computador como recurso didático. Cinco professoras (ou seja, 55,55\%) culpabilizam o governo estadual por não terem sido capacitadas para tal finalidade. Aqui, constata-se a representação social coletiva de que o outro, no caso, o governo é sempre culpado pelos fracassos e incompetências dos cidadãos, como se buscar conhecimentos e tentar se aprimorar em sua própria profissão fosse responsabilidade de outrem.

Estes dados revelam a argumentação de Chaib (2002) quando o mesmo relaciona a falta de preparo do professor ao principal entrave em sua prática docente.

\section{4) Computadores como elementos de decoracão nas escolas.}

Nas práticas pedagógicas de algumas professoras, a sala de informática não é utilizada pelos seguintes motivos por elas apresentados: falta de sala de informática em condições de uso (6 professoras) e indisciplina dos alunos.

Carneiro (2002) acredita ser importante a compreensão das representações que os docentes têm sobre a introdução da informática da escola para se ter um direcionamento de ações a serem executadas para o bem comum.

\section{ALGUMAS CONCLUSÕES PARCIAIS}

Pode-se verificar que apesar da diversidade existente de opções de uso da tecnologia como ferramenta didática, o uso do computador, especificamente, ainda não se configurou como uma realidade em nossas escolas.

Contudo, de acordo com Leite (2003), faz-se necessária a escolha precisa do professor sobre quais materiais, técnicas, ferramentas ou dispositivos serão realmente eficientes para promover a aprendizagem dos conteúdos que ele irá trabalhar em determinadas situações didáticas. É preciso identificar, segundo a autora, instrumentos que promovam a aprendizagem com eficiência, significado e de forma prazerosa. Um destes instumentos é o computador.

Como vimos na teoria e na prática, a inclusão tecnológica nem sempre vem aliada à inclusão digital, conforme Lévy (1998).

Para que o professor obtenha êxito, é necessário que o mesmo se prepare previamente, 
planejando conscientemente a sua aula, com vistas a motivar os estudantes e, assim, alcançar os objetivos propostos, pois a simples presença da tecnologia na sala de aula, por si só, não garante a qualidade do ensino, nem dinamismo à prática pedagógica.

Sem a pretensão de esgotar o tema, este estudo busca contribuir para novas reflexões.

\section{REFERÊNCIAS}

ALMEIDA, F.J. Educação e informática: os computadores na escola. São Paulo: Cortez, 2005.

BELLONI, M.L. O que é mídia-educação. Campinas: Autores Associados, 2001.

CARNEIRO, R. Informática na educação: representações sociais do cotidiano. São Paulo: Cortez, 2002.

CHAIB, M. Franskstein na sala de aula: as representações sociais docentes sobre informática. Nuances, n.8, set.2002, p.47-64.

CHAVES, E.C.; SETZER, V.W. O uso de comutadores em escolas. S.Paulo: Scipione, 1998.

CYSNEIROS, P.G. Novas tecnologias na educação. Recife: [s.ed.], 1998.

DURKHEIM, E. 1970. Representações individuais e coletivas. In: Sociologia e Filosofia (E. Durkheim). Rio de Janeiro: Forense Universitária, p.15-49.

HAETINGER, M.G. Informática na educação: um olhar criativo. Porto Alegre: Instituto Criar Ltda, 2003.

LEITE, L.S. (Coord). Tecnologia educacional: descubra suas potencialidades na sala de aula. Petrópolis: Vozes, 2003.

LÉVY, P. As tecnologias da inteligência: o futuro do pensamento na era da informática. Rio de Janeiro: Editora 34, 1993.

. A inteligência coletiva: por uma antropologia no ciberespaço. São Paulo: Loyola, 1998.

MINAYO, M.S. (0rg). Pesquisa social: teoria, método e criatividade. Petrópolis: Vozes, 2001.

MOSCOVICI, S. A representação social da psicanálise. Rio de Janeiro: Zahar Editores, 1978. 
Sobre representações sociais. Tradução: Clélia Nascimento Schulze. Núcleo de Psicologia Social, Departamento de Psicologia: UFSC, 1985.

A psicologia social. Barcelona: Paidós, 1986.

Das representações coletivas às representações sociais: elementos para uma história. In: D. JODELET (Org.). As representações sociais. Rio de Janeiro: UERJ, 2001. p.18-66.

OLIVEIRA, R. Informática educativa. Campinas: Papirus, 1997.

VALENTE, A. Informática na educação: conformar ou transformar a escola. Florianópolis: CED/UFSC, 1996.b 